\title{
Impact of an educational intervention to improve adherence to the recommendations on safe infant sleep
}

\author{
Manuel Rocca Rivarola M.D. ${ }^{a}$, Pablo Reyes M.D. ${ }^{a}$, Caterina Henson M.D. ${ }^{a}$, \\ Juan Bosch M.D. ${ }^{a}$, Pablo Atchabahian M.D. ${ }^{b}$, Ricardo Franzosi M.D. ${ }^{c}$, \\ Carla Di Pietro M.D. ${ }^{d}$, Dra. Constanza Balboni M.D. ${ }^{d}$ and Norberto Giglio M.D. ${ }^{d}$
}

\begin{abstract}
Introduction. In developed countries, public campaigns promoting recommendations on safe infant sleep increased adherence to the supine sleeping position to more than $70 \%$ and, at the same time, reduced the incidence of sudden infant death syndrome by $53 \%$.

Objective. To determine the impact, at 60 days of life, of an educational intervention conducted in maternity centers aimed at improving adherence to the recommendations on safe infant sleep. Population, material and methods. Intervention study with historical control conducted between February $1^{\text {st }}$ and September $30^{\text {th }}$ of 2014 at the Maternity Center of Hospital Meisner and Hospital Universitario Austral. The intervention was called "crib card" and consisted in training health care team members and providing families with information on safe infant sleep by means of lessons, written material and using stickers on cribs.
\end{abstract}

Results. Five hundred and fifty newborn infants were included. After the intervention, a $35 \%$ increase in the supine sleeping position $(p<0.0001)$ was observed; exclusivebreastfeeding increased by $11 \%(p=0.01)$; and co-sleeping decreased from $31 \%$ to $18 \%$ ( $p<0.0005)$. No differences were observed in relation to bedroom sharing, living with tobacco users, or pacifier use at 60 days of life.

Conclusions. The educational intervention was useful to improve adherence to the recommendations on safe sleep at 60 days of life: using the supine position and breastfeeding improved, and the rate of co-sleeping decreased. No changes were observed in the number of household members who smoke, bedroom sharing, and pacifier use.

Key words: sudden infant death syndrome, SIDS, education, crib death.

http:/ /dx.doi.org/10.5546/aap.2016.eng.223

E-mail address:

Manuel Rocca Rivarola, M.D.mrrivarola@cas. austral.edu.ar

Funding:

None.

Conflict of interest:

None.

Received: 08-25-2015

Accepted: 12-09-2015 of age, apparently occurring during (SIDS) is one of the leading causes of post-neonatal mortality in many countries, including Argentina. ${ }^{1,2}$

SIDS is defined as the sudden death of an infant less than 1 year sleep and that cannot be explained after a thorough investigation is conducted, including a complete autopsy, examination of the death scene, and the review of the clinical history. ${ }^{2}$

In the early 1990s, several countries implemented educational programs to inform and raise the population's awareness about risk factors and child rearing practices associated with SIDS. The programs were initially focused on the prone sleeping position and pre- and postnatal tobacco smoke exposure, with the subsequent addition of the advantages of breastfeeding and other elements. As a result, the incidence of SIDS decreased, in average, by $53 \%$, which led to a $39 \%$ reduction in postneonatal mortality. ${ }^{3,4}$

In Argentina, according to a survey conducted by the Ministry of Health in $2010,59.5 \%$ of babies discharged from maternity centers slept in the supine position. ${ }^{5,6}$ In this regard, in the District of Pilar, results were similar: $61.2 \%$ of babies slept in the supine position at the time of discharge, but adherence was observed to decrease at 4 months old, with only $21.2 \%$ of babies sleeping in the supine position. ${ }^{7}$

Considering the relevance of educational programs to reduce the risk for SIDS and the resulting adherence to healthy child rearing practices observed in a prior study conducted in the District of Pilar, ${ }^{7}$ an educational intervention was developed in this district to improve adherence to the main recommendations for reducing SIDS cases.

The main objective of this study 
was to assess the impact, at 60 days of life, of an educational intervention conducted in maternity centers to improve adherence to the recommendations on safe infant sleep in terms of the habit of supine sleeping position, exclusive breastfeeding, tobacco smoke exposure, cosleeping, bedroom sharing, sleeping place (crib or stroller/infant car seat) and pacifier use.

\section{MATERIAL AND METHODS}

The research was designed as an intervention study with historical control. The study was conducted at Hospital Municipal Comodoro Meisner and Hospital Universitario Austral (HUA). These hospitals cater for $95 \%$ of all childbirths in the District of Pilar, with 4100 annual births occurred at the Hospital Municipal Comodoro Meisner and 2100, at the HUA. A survey was administered in the maternity center and at 60 days of life (Annex). Inclusion criteria: all live newborn infants with $>36$ weeks of gestation born in Hospital Municipal Comodoro Meisner and the HUA whose mothers' place of residence was in the District of Pilar. Infants with major congenital malformations and/or hospitalized in the Neonatal Intensive Care Unit for more than 10 days were excluded given their special care needs.

The study was conducted in three stages: Stage 1: Baseline status observation. Stage 2: Educational intervention. Stage 3: Postintervention status observation (all stages conducted between 02/01/2014 and 09/30/2014).

Stage 1. SIDS prevention practices were assessed using a survey administered between February $1^{\text {st }}$ and April $30^{\text {th }}$. At the time of discharge from the maternity center, demographic and clinical characteristics of mothers and newborn infants were collected. Sixty days after discharge, definite data for the survey on prevention practices were collected on the telephone. Given that none of the two sites had an institutional policy on safe sleep in place, the group defined as control group received the hospital's usual recommendations orally as per each health care provider's criterion.

Stage 2. The educational intervention was conducted between 05/01/2014 and 09/30/2014. The intervention consisted in providing the newborn infants' mothers and family members with information on the importance of adhering to SIDS prevention practices. Attending group and individual lessons given by trained health care providers was established as a requirement for discharge. In addition, a visual support was used, which consisted in a "crib card" placed on cribs and posters with visual information on hallways and waiting rooms. ${ }^{8}$ Written material with the information provided in the posters on safe sleep practices was also delivered to participating families, and printed material for one year was left at each site according to the estimated number of births (Figures 1 and 2).

All health care staff members responsible for providing information to families received, initially, the same training so that the process was homogeneous. Training was provided by pediatricians, article authors and collaborators in accordance with the guidelines on SIDS prevention recommendations of the American Academy of Pediatrics and the Argentine Society of Pediatrics. ${ }^{7}$

Health care providers responsible for providing information to newborn infants' families included physicians (pediatricians, neonatologists, obstetricians, residents), licensed midwives, general nurses and pediatric nurses. Training took place in courses and workshops offered during the different working shifts.

FIGURE 1. Safe sleep poster and printed material

\section{GUIDELINES ON SAFE INFANT SLEEP}

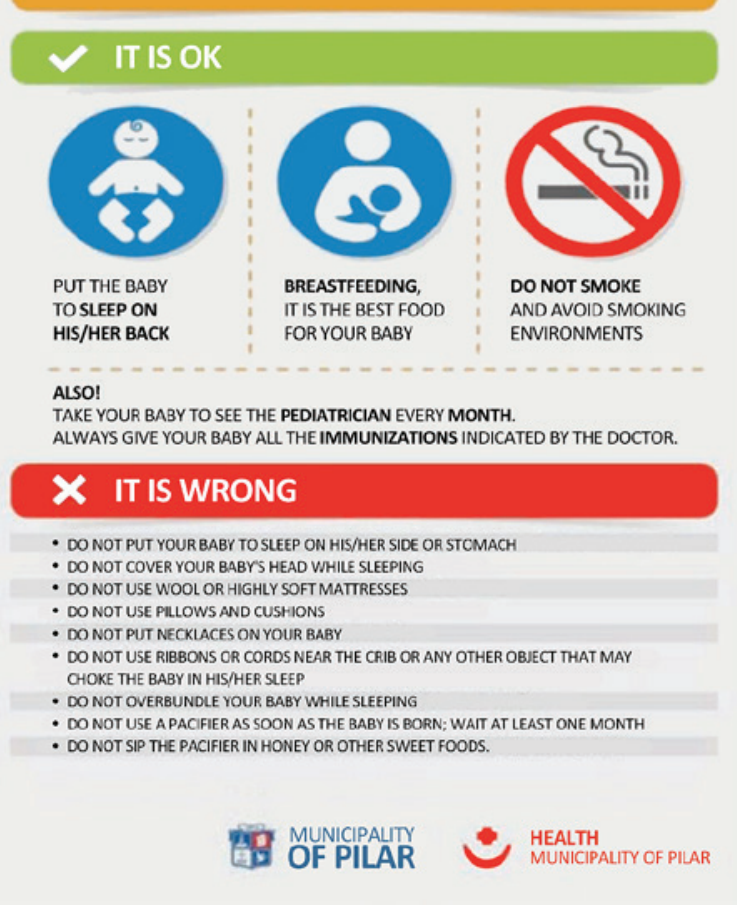


Stage 3. The methodology was the same used for stage 1: a personal survey administered in the maternity center followed, at 60 days, by a telephone survey, between $07 / 01 / 2014$ and $09 / 30 / 2014$. This group received the educational intervention and was defined as the intervention group.

For both the control and the intervention groups, the primary outcome measure was the supine sleeping position at 60 days after discharge from the maternity center. The prevention practices described for the main objective and demographic and clinical characteristics of mothers and newborn infants at the time of discharge from the maternity center were also assessed.

The questionnaire was based on the adapted and validated survey sample used in the International Child Care Practices Study ${ }^{9,10}$ (see Annex 1). In both groups, if families admitted at the 60-day survey that they had not adhered to safe sleep practices, they were reminded of their importance and the relevance of visiting their pediatrician.

Assuming a $15 \%$ increase in the supine sleeping position and based on the $21 \%$ rate at 4 months old from the previously published study, ${ }^{7}$ it was estimated that 196 patients in each group (control and intervention) would allow to detect a $10 \%$ or higher difference between both groups, with an $80 \%$ power and a $5 \%$ significance.

\section{Statistical analysis}

A descriptive analysis of demographic and prevention outcome measures was done for both groups: control and intervention.

\section{FIGURE 2. Sticker placed on each crib}

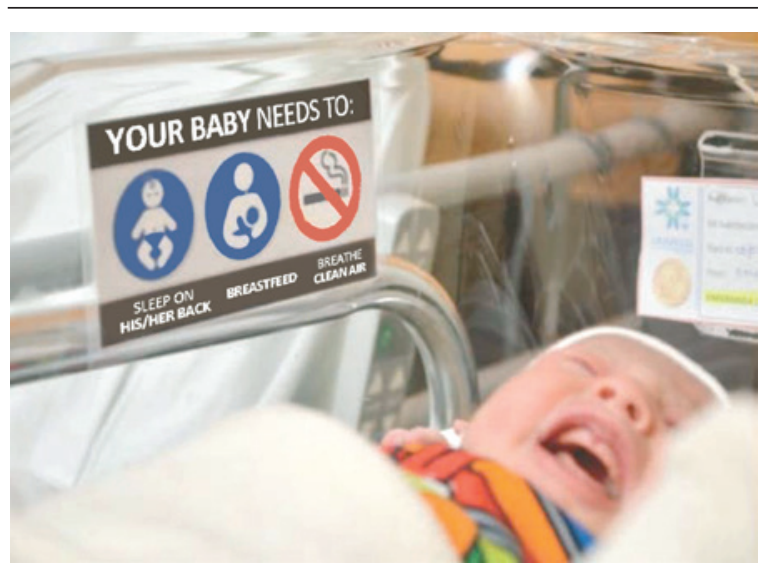

Categorical outcome measures in both groups were compared using the $\chi^{2}$ test. Continuous outcome measures were compared using the Mann-Whitney test or the t-test, according to compliance with assumptions of normality, and verified using the Shapiro-Wilk test. In all cases, a 5\% significance level was established.

\section{Ethical aspects}

Visual information, questionnaires and the working protocol were approved by the Institutional Review Board of the School of Biomedical Sciences of Universidad Austral. Besides, all mothers, fathers or legal tutors who agreed to participate signed the corresponding informed consent.

\section{RESULTS}

Five hundred and fifty newborn infants were included during the study period: 283 in the control group and 267 in the intervention group. At 60 days, data were collected from 499 infants, accounting for a $9.2 \%$ loss (Figure 3). Such loss was the result of problems with the telephone contact. According to municipal reporting systems, no deaths occurred in our population throughout the study period.

Table 1 describes the demographic and clinical characteristics of mothers and newborn infants in both groups and the outcomes for sleeping position, exclusive breastfeeding and pacifier use at the time of discharge from the maternity center.

In relation to the sleeping position at 60 days of life, $42 \%$ of infants in the control group and $77 \%$ in the intervention group slept in the supine position $(p<0.0001)$ (Table 2).

Fifty per cent of infants slept in the lateral position in the control group versus 19\% in the intervention group $(p<0.04)$. In both groups (control and intervention), 93\% of babies shared the bedroom with their parents. Co-sleeping was practiced by $31 \%$ of participants in the control group and by $17 \%$ in the intervention group $(p=0.0005)$ (Table 2). In relation to the sleeping place, it was observed that $15 \%$ of infants in the control group slept in a stroller/infant car seat, versus $2 \%$ in the intervention group.

At 60 days of life, $60 \%$ of infants in the control group and $71 \%$ in the intervention group were exclusively breastfed $(p=0.01)$ (Table 2$)$.

No differences were observed in the proportion of infants who lived together with tobacco users: $27 \%$ in both groups. And no differences were identified in terms of pacifier use 
at 60 days when comparing the control group to the intervention group.

\section{DISCUSSION}

Although SIDS is attributed to multiple causes, the most commonly recognized theory is the "triple risk hypothesis". This hypothesis includes a vulnerable infant, defined by a series of conditions: male sex, preterm birth, prenatal exposure to tobacco and alcohol, in addition to serotonergic system alterations, channelopathies, and polymorphisms or mutations, in association with a critical developmental period (from 2 to 6 months old) and exogenous factors, like sleeping on their stomach/side, co-sleeping, overheating, environmental tobacco smoke.

A convergence of these factors leads to failure in the normal protective response to hypoxemia events. ${ }^{11}$

Several countries around the world have developed different programs, including the USA,
Norway, New Zealand, Canada and the United Kingdom, where the prevalence of the supine sleeping position at 4 months old is over $70 \% .^{12-15}$

A special mention should be made to side sleeping, which also decreased significantly in the intervention group at 60 days of life. Although the side sleeping position was recommended in early SIDS prevention campaigns, Scragg and Mitchell in 1998 and Gilbert in 2005 demonstrated that this position was significantly associated with SIDS. ${ }^{13,16}$

To date, it is hard to modify the sleeping position habit because there is still fear that the supine position may be unsafe, increase the possibility of aspiration syndromes ${ }^{17}$ or result in a higher number of arousals. ${ }^{18}$

Based on these assumptions, some investigators have described that the resistance to adopt the supine sleeping position is more commonly observed among the young, Hispanic population with a low socioeconomic level. ${ }^{10,12,19}$

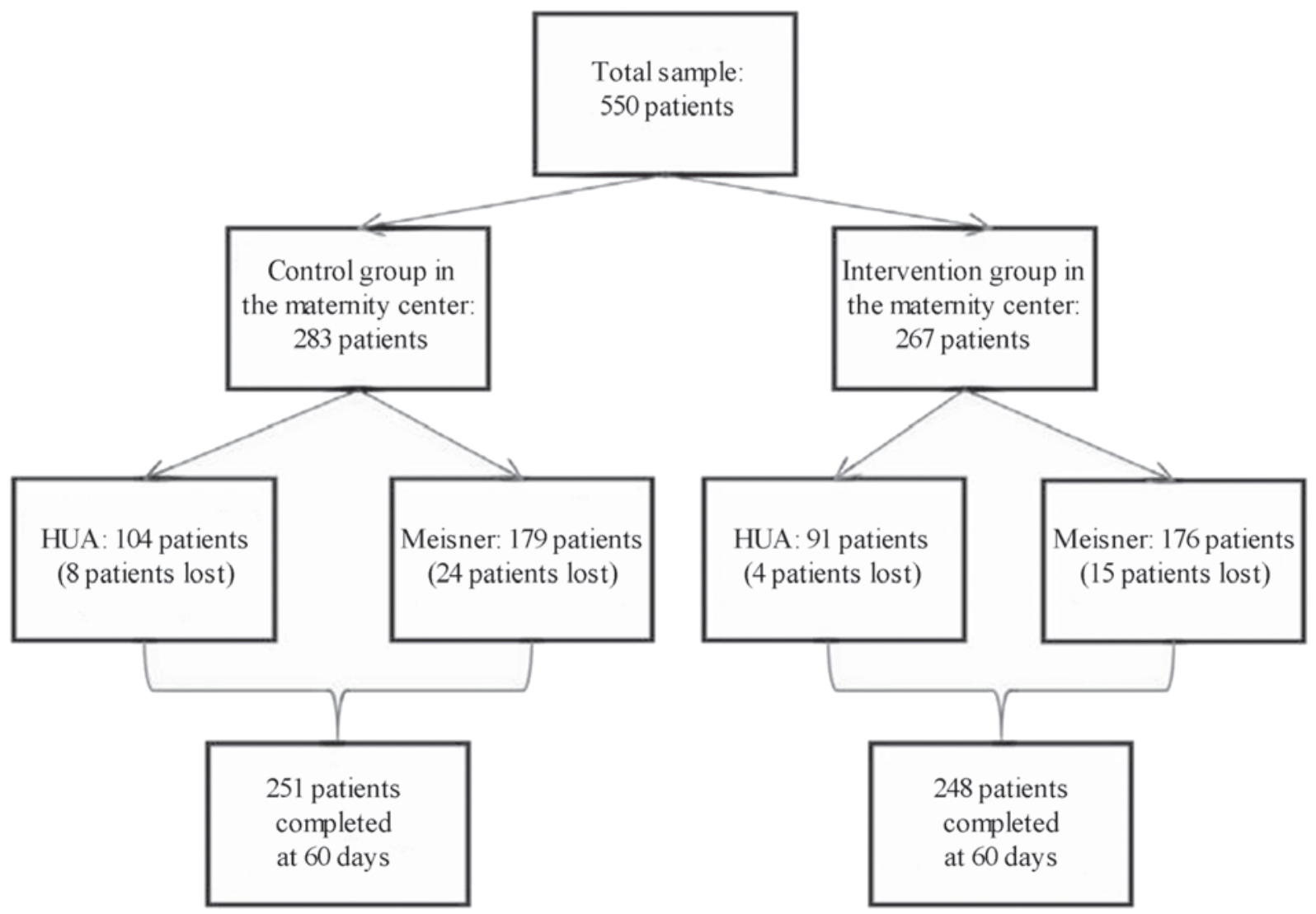

HUA: Hospital Universitario Austral. 
At present, we decided to include the socalled "crib card", proposed by S. Cowan, from New Zealand, in the Proyecto Vinculo conducted in Argentina and supported by the Ministry of Health, the Argentine Society of Pediatrics and UNICEF. ${ }^{6}$ The project's main message was: "Your baby needs to sleep on his/her back, breastfeed and breathe clean air". This is a lowcost intervention and promotes communication between health care teams and families.

Based on the sequence of this message, in addition to a favorable change in sleeping habits, we have also observed an increase in the number of exclusively breastfed infants, but it was not possible to identify changes in the smoking habit of people who share the household.

The effects of tobacco smoke exposure and use on perinatal and postnatal health have been clearly established, which include a low birth weight, preterm birth and increased SIDS risk. ${ }^{20}$ The risk of sudden death is four times higher among infants born to smoking mothers, and twice as high among those whose mothers are exposed to second-hand smoking, making the impact on passive smokers also noteworthy. ${ }^{21-24}$ These data evidence a serious maternal and perinatal health problem, which becomes even more concerning once environmental tobacco exposure comes into the picture: 1 in every 4 women lives with tobacco users, similar to the

TABLE 1. Baseline characteristics of both groups

\begin{tabular}{|c|c|c|c|c|}
\hline & & Control $(n=283)$ & Intervention $(n=267)$ & p \\
\hline Maternal age & (Mean/SD) & $26.59(6.43)$ & $26.98(6.14)$ & NS \\
\hline \multirow[t]{3}{*}{ Marital status } & Married (n/\%) & $41(16 \%)$ & $31(12.5 \%)$ & NS \\
\hline & Living with a couple $(\mathrm{n} / \%)$ & $186(73 \%)$ & $191(77 \%)$ & NS \\
\hline & Single $(\mathrm{n} / \%)$ & $29(11 \%)$ & $26(10.5 \%)$ & NS \\
\hline \multirow[t]{3}{*}{ Level of maternal education } & Complete primary education & $59(23.5 \%)$ & $43(17 \%)$ & 0.028 \\
\hline & Incomplete secondary education $(\mathrm{n} / \%)$ & $84(33.5 \%)$ & $91(37 \%)$ & NS \\
\hline & Complete sec./tert./univ. education (n/\%) & $108(43 \%)$ & $114(46 \%)$ & NS \\
\hline Prior pregnancies & (Mean/SD) & $2.41(1.38)$ & $2.57(1.57)$ & NS \\
\hline Number of children & (Mean/SD) & $2.31(1.38)$ & $2.44(1.52)$ & NS \\
\hline Female newborn infants & $(\mathrm{n} / \%)$ & $115(46.4 \%)$ & $127(49.2 \%)$ & NS \\
\hline C-section & $(\mathrm{n} / \%)$ & $76(31 \%)$ & $81(31.4 \%)$ & NS \\
\hline Weight at birth (g) & $($ Mean/SD) & $3353(592)$ & $3377(546)$ & NS \\
\hline \multicolumn{2}{|l|}{ Number of people living together } & $5(2.03)$ & $4.95(1.92)$ & NS \\
\hline \multicolumn{2}{|c|}{5 or more antenatal care visits during pregnancy $\quad(n / \%)$} & $180(72 \%)$ & $205(80 \%)$ & NS \\
\hline \multicolumn{2}{|l|}{ Smoking during pregnancy } & $21(8.5 \%)$ & $13(5 \%)$ & NS \\
\hline \multicolumn{2}{|l|}{ Pacifier use while at maternity } & $66(27 \%)$ & $47(18 \%)$ & 0.0234 \\
\hline \multicolumn{2}{|l|}{ Exclusive breastfeeding } & $238(96 \%)$ & $244(95 \%)$ & NS \\
\hline \multicolumn{2}{|l|}{ Supine sleeping position } & $187(76 \%)$ & $210(82 \%)$ & NS \\
\hline
\end{tabular}

SD: standard deviation; NS: not significant.

TABLE 2. Characteristics at 60 days in both groups

\begin{tabular}{|c|c|c|c|c|}
\hline & & Control $(n=251)$ & Intervention $(n=248)$ & p \\
\hline Bedroom sharing & $(\mathrm{n} / \%)$ & $230(91.6 \%)$ & $224(90.3 \%)$ & NS \\
\hline Co-sleeping & $(\mathrm{n} / \%)$ & $78(31 \%)$ & $42(17 \%)$ & $<0.0005$ \\
\hline \multirow[t]{3}{*}{ Sleeping position } & Supine $(\mathrm{n} / \%)$ & $105(42 \%)$ & $191(77 \%)$ & $<0.0001$ \\
\hline & Lateral (n/\%) & $125(50 \%)$ & $47(19 \%)$ & $<0.04$ \\
\hline & Prone $(\mathrm{n} / \%)$ & $21(8 \%)$ & $10(4 \%)$ & NS \\
\hline \multirow[t]{2}{*}{ Sleeping place } & Crib (n/\%) & $137(54 \%)$ & $190(76 \%)$ & 0.0003 \\
\hline & Infant car seat/stroller (n/\%) & $38(15 \%)$ & $6(2 \%)$ & \\
\hline \multirow[t]{3}{*}{ Feeding modality } & Exclusive breastfeeding (n/\%) & $150(60 \%)$ & $174(71 \%)$ & $<0.01$ \\
\hline & Mixed feeding $(\mathrm{n} / \%)$ & $82(33 \%)$ & $63(25 \%)$ & NS \\
\hline & Artificial feeding (n/\%) & $19(7 \%)$ & $11(4 \%)$ & NS \\
\hline Pacifier use & $(\mathrm{n} / \%)$ & $130(51.8 \%)$ & $139(56 \%)$ & NS \\
\hline Living together with a tobacco user & $(\mathrm{n} / \%)$ & $68(27.1 \%)$ & $67(27 \%)$ & NS \\
\hline
\end{tabular}

NS: not significant. 
results published two years before. ${ }^{7}$ The physical, psychological and social complexity involved in addiction cessation ${ }^{21-23}$ may account for the failure of the intervention in this regard.

In relation to the use of pacifiers, a significant reduction was observed in the intervention group at the maternity center, which may be the result of a clearer explanation on the right time to start using them. However, no differences have been identified between both groups in terms of pacifier use at 60 days old, so this message should be reevaluated. Although the information provided is correct, future campaigns should convey a positive rather than prohibitory message. Messages communicated in the first days of the infant's life should encourage attachment and exclusive breastfeeding, and also promote pacifier use once breastfeeding has been well enough established. ${ }^{4,25,26}$

Consistent with our results, among the Argentine population it is very common that parents share the bedroom with their babies, either because of their attachment, a lack of space, or fear of SIDS itself, and this may account for the high percentage of bedroom sharing observed in both groups.

Lastly, the proportion of co-sleeping in the intervention group was lower than in the control group, even though it was not specifically indicated in the "crib card" and printed material. The risks generated by co-sleeping were orally transmitted to the families in the maternity center.

There is evidence that co-sleeping poses a high risk in certain situations: if practiced on a couch, sofa or very soft mattress, with infants younger than 3 months old or preterm infants, or by a father or mother who smokes or has used alcohol, drugs or sedatives. ${ }^{27,28}$

In Argentina, the Argentine Society of Pediatrics' recommendations from $2000^{29}$ were not conclusive on this matter, but the 2015 considerations on safe sleep suggested that, based on available evidence, health team members should unanimously recommend bedroom sharing with no co-sleeping for the safe sleep of infants and preterm babies. ${ }^{5}$

Although both populations share similar characteristics (Figure 2), which allows outcomes to be compared, our study may be biased because it is an open-label educational strategy, and for this reason it may be very difficult to blind outcome assessment. In addition, to a certain extent, favorable results observed in the intervention group may have been partially due to the difference in the proportion of mothers who had completed primary education in this group.

Given the characteristics of the usual dissemination of information that takes place in a hospital among the different families through social exchange, it was extremely difficult to implement the intervention in one group and, at the same time, establish a control group. For this reason both groups were assessed sequentially, and this strategy may somehow be biased.

Anyhow, the temporal association between the intervention and outcomes, the content of the message and the presence of a control group, even with a certain level of weakness, reinforce the hypothesis that this educational strategy has been effective.

\section{CONCLUSIONS}

The educational intervention implemented in the maternity centers proved to be a useful tool to improve adherence to the recommendations at 60 days of life: significant improvements were observed in the use of the supine sleeping position and breastfeeding, and in the reduction of cosleeping. No significant changes were observed in relation to living with a tobacco user, sharing the bedroom and using a pacifier at 60 days of life.

\section{Acknowledgments}

We would like to thank Gabriel Musante, M.D. and Magdalena Caballero, B.S.

\section{REFERENCES}

1. Krous HF, Beckwith JB, Byard RW, Rognum TO, et al. Sudden infant death syndrome and unclassified sudden infant deaths: a definitional and diagnostic approach. Pediatrics 2004;114(1):234-8.

2. Argentina. Ministerio de Salud de la Nación. Análisis de la Mortalidad Materna e Infantil. República Argentina 2003 2012. [Accessed on: December 10, 2015]. Available at: http:/ /www.msal.gov.ar/images / stories / bes / graficos/0000000616cnt-analisis_mortalidad_materno_ infantil_argentina-2003-2012.pdf.

3. American Academy of Pediatrics AAP Task Force on Infant Positioning and SIDS: Positioning and SIDS. Pediatrics 1992;89(6 Pt 1):1120-6.

4. Task Force on Sudden Infant Death Syndrome, Moon RY. SIDS and other sleep-related infant deaths: expansion of recommendations for a safe infant sleeping environment. Pediatrics 2011:128(5):e1341-67.

5. Jenik A, Grad E, Orazi V, Sapoznicoff L, et al. Consideraciones sobre el sueño seguro del lactante. Grupo de Trabajo en Muerte Súbita e Inesperada del Lactante de la Sociedad Argentina de Pediatría. Buenos Aires: Sociedad Argentina de Pediatría; 2015. [Accessed on: December 10, 2015]. Available at: http://www.sap.org.ar/docs/ profesionales/consensos/consideracionesSueno.pdf.

6. Información para la comunidad: tarjeta cuna [Internet]. Fundación para el Estudio y la Prevención de la Muerte 
Infantil y Perinatal. [Accessed on: December 10, 2015]. Available at: http://www.sids.org.ar/gdp51.htm.

7. Rocca R M, Bosch F J, Henson D C, Reyes H P, et al. Evaluación de la adherencia a las recomendaciones para disminuir el riesgo de Síndrome de Muerte Súbita del lactante. Rev Chil Pediatr 2014;85(4):462-9.

8. Cowan S, Pease A, BennettS. Usage and impact of an online education tool for preventing sudden unexpected death in infancy. J Paediatr Child Health 2013;49(3):228-32.

9. Task Force on Sudden Infant Death Syndrome, Moon RY. SIDS and other sleep-related infant deaths: expansion of recommendations for a safe infant sleeping environment. Pediatrics 2011;128(5):1030-9.

10. Blair PS, Sidebotham P, Berry PJ, Evans M, et al. Major epidemiological changes in sudden infant death syndrome: a 20-year population-based study in the UK. Lancet 2006;367(9507):314-9.

11. Kinney HC. Brainstem mechanisms underlying the sudden infant death syndrome: evidence from human pathologic studies. Dev Psychobiol 2009;51(3):223-33.

12. Pickett KE, Luo Y, Lauderdale DS. Widening social inequalities in risk for sudden infant death syndrome. $A m$ J Public Health 2005;95(11):1976-81.

13. Scragg RK, Mitchell EA. Side sleeping position and bed sharing in the sudden infant death syndrome. Ann Med 1998;30(4):345-9.

14. Mitchell EA, Tonkin S. Publicity and infants' sleeping position. BMJ 1993;306(6881):858.

15. Hiley CM,Morley CJ.Evaluation of government's campaign to reduce risk of cot death. BMJ 1994;309(6956):703-4.

16. Gilbert R, Salanti G, Harden M, See S. Infant sleeping position and the sudden infant death syndrome: systematic review of observational studies and historical review of recommendations from 1940 to 2002. Int J Epidemiol 2005;34(4):874-87.

17. Krous HF, Masoumi H, Haas EA, Chadwick AE, et al. Aspiration of gastric contents in sudden infant death syndrome without cardiopulmonary resuscitation. J Pediatr 2007;150(3):241-6.
18. Franco P, Groswasser J, Sottiaux M, Broadfield E, et al. Decreased cardiac responses to auditory stimulation during prone sleep. Pediatrics 1996;97(2):174-8.

19. Lesko SM, Corwin MJ, Vezina RM, Hunt CE, et al. Changes in sleep position during infancy: a prospective longitudinal assessment. JAMA 1998;280(4):336-40.

20. Hofhuis W, de Jongste JC, Merkus PJ. Adverse health effects of prenatal and postnatal tobacco smoke exposure on children. Arch Dis Child 2003;88(12):1086-90.

21. McDonnell-Naughton M, McGarvey C, O'Regan M, Matthews T. Maternal smoking and alcohol consumption during pregnancy as risk factors for sudden infant death. Ir Med J 2012;105(4):105-8.

22. Liebrechts-Akkerman G, Lao O, Liu F, van Sleuwen BE, et al. Postnatal parental smoking: an important risk factor for SIDS. Eur J Pediatr 2011;170(10):1281-91.

23. Owen L, McNeill A, Callum C. Trends in smoking during pregnancy in England, 1992-7: quota sampling surveys. BMJ 1998;317(7160):728.

24. Fleming P, Blair PS. Sudden Infant Death Syndrome and parental smoking. Early Hum Dev 2007;83(11):721-5.

25. Vennemann MM, Bajanowski T, Brinkmann B, Jorch G, et al. Does breastfeeding reduce the risk of sudden infant death syndrome? Pediatrics 2009;123(3):e406-10.

26. Hauck FR, Omojokun OO, Siadaty MS. Do pacifiers reduce the risk of sudden infant death syndrome? A meta-analysis. Pediatrics 2005;116(5):e716-23.

27. Vennemann MM, Hense HW, Bajanowski T, Blair PS, et al. Bed sharing and the risk of sudden infant death syndrome: can we resolve the debate? J Pediatr 2012;160(1):44-8.

28. Carpenter R, McGarvey C, Mitchell EA, Tappin DM, et al. Bed sharing when parents do not smoke: is there a risk of SIDS? An individual level analysis of five major casecontrol studies. BMJ Open 2013;3(5):e002299.

29. Grupo de Trabajo en Muerte Súbita del Lactante. Nuevas recomendaciones para la disminución del riesgo de muerte súbita del lactante. Arch Argent Pediatr 2000;98(4):239-43. 


\section{ANNEX \\ CHILD REARING PRACTICES IN THE DISTRICT OF PILAR}

INITIAL SURVEY (DURING HOSPITALIZATION)

Date of survey:

\section{Maternal data}

Mother's first and last name:

Father's first and last name:

Address:

Contact number (1):

Contact number (2):

E-mail address:

\section{Maternal age (in years)}

$15-20$

20-25

25-30

30-35

$35-40$

$>40$

\section{Marital status}

Single

Living with a couple

Married

Separated

Widow

\section{Level of maternal education}

Incomplete primary education

Complete primary education

No education

Incomplete secondary education

Complete secondary education

Tertiary or university education

Number of pregnancies (including current pregnancy)

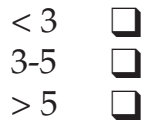

Number of children (including current newborn infant)

$\begin{array}{ll}<3 & \square \\ 3-5 & \square \\ >5 & \square\end{array}$

Number of antenatal care visits during current pregnancy

$\begin{array}{ll}<3 & \square \\ 3-5 & \square \\ >5 & \square\end{array}$

\section{Smoking during pregnancy}

No

Yes

Cigarettes/day:

$$
\begin{aligned}
& <5 \\
& 5-10 \\
& >10
\end{aligned}
$$

Alcohol use during pregnancy

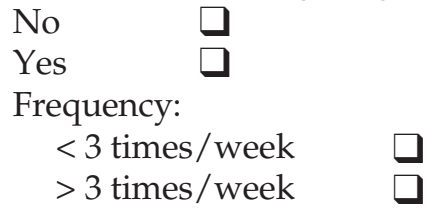

\section{Social background}

Type of housing:

Brick

Wooden

Metal sheet

Shack

Sewer:

$$
\begin{array}{ll}
\text { Yes } & \square \\
\text { No } & \square
\end{array}
$$

Drinking water:

Yes

No

No. of bedrooms

Total no. of household members

Newborn history

First and last name:

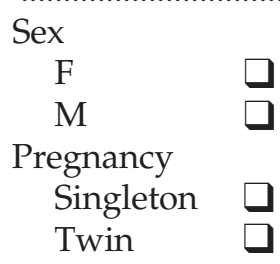


Gestational age in weeks:

Childbirth

Vaginal delivery

C-section

Weight at birth:

$<1500$ g

$1500-2000 \mathrm{~g}$

2000-3000 g

$3000-4000 \mathrm{~g}$

$>4000 \mathrm{~g}$

Apgar score :

Vigorous (7-10)

Depressed $(<6)$

Hospitalization in Neonatal Care Unit:

Yes

No

\section{Child rearing practices}

How did you feed your baby today?

Exclusive breastfeeding

Breastfeeding + formula

supplementation

Breastfeeding + cow's milk

supplementation

Cow's milk bottle

Formula bottle

Did your baby use a pacifier today?

Yes

No

What position did your baby sleep last night?

On his/her back

On his/her side

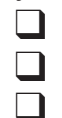

On his/her stomach

\section{FOLLOW-UP SURVEY (at 2 months)}

\section{Child rearing practices}

Feeding:

Exclusive breastfeeding

Breastfeeding + formula

supplementation

Breastfeeding + cow's milk

supplementation

Cow's milk bottle

Formula bottle

Supplementation with vitamins A, C, D:

Yes

No
Did your baby use a pacifier last night?

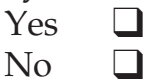

In which room (bedroom, etc.) did your baby sleep last night?

In his/her own bedroom

In his/her parents' bedroom

In a room with his/her parents and other people (siblings, family members)

In a room with other people

(siblings, family members)

Did your baby share the bed with other people?

No

Yes, his/her mother

Yes, his/her mother and father

Yes, other people

Where did your baby sleep last night?

Bed

Crib/portable crib

Stroller

What position did your baby sleep last night?

On his/her back

On his/her side

On his/her stomach

Were there any pillows, cushions, or staffed toys in the place where your baby slept last night?

No

Yes

Does any household member smoke?

No

Yes

How many in total?

Mother

Father

Other
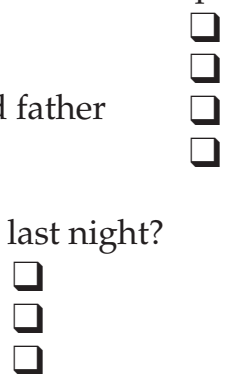